УДК 537.525 .5

DOI https://doi.org/10.32838/2663-5941/2020.4/26

Фролова Л. $A$.

Український державний хіміко-технологічний університет

\title{
ОПТИМІЗАЦІЯ УМОВ ФОТОКАТАЛІТИЧНОГО ОКИСЛЕННЯ 4-НІТРОФЕНОЛУ
}

Розвиток промислових технологій та сільськогосподарської діяльності призвів до вивільнення органічних сполук, що є потенційною загрозою для водних екосистем та здоров'я людини. Серед них такі забруднювачі, як пестициди, продукти хлорування та спалювання природного палива, фармацевтичні засоби та засоби особистої гігієни. Щоб підвищити ефективність традиційних методів обробки забруднених стічних вод, використовують передові прочеси окислення, які забезпечують потужне руйнування забруднювачів навколишнього середовища завдяки утворенню активних радикалів. Серед них фотокаталітичні прочеси є перспективними завдяки високому ступеню деградаиії стійких забруднюючих речовин.

Крім того, масштабування хімічних технологій - від лабораторних досліджень до промислового виробництва - є складним завданням і вимагає визначення оптимальних умов проведення прочесу, глибокого знання механізму реакиій, що відбуваються в системі. Це необхідно для конструкторської та технологічної розробки основних апаратів та визначення оптимальних умов їх експлуатаціï.

У статті розглянуто прочес фотокаталітичного розкладання 4-нітрофенолу, в присутності феритового каталізатору.

Експерименти проводилися з використанням реактора, що був обладнаний УФ-випромінювачем. Кониентрацію 4-нітрофенолу визначали за допомогою спектрофотометра UV 5800 PC. Статистична модель була розроблена за допомогою програмного пакета STATISTICA 10 і базувалася на основних реакиіях, що відбувалися під дією УФ-випромінювання в присутності феритового каталізатора. Розраховані значення концентрачій та ступеня розкладання 4-нітрофенолу були підтверджені експериментальними результатами. Отримана статистична модель, що є адекватною. За допомогою методу центрального композиційного планування експерименту визначені також оптимальні параметри процесу, а саме конщентрації фотокаталізатора, перекису водню $і$ часу обробки.

Ключові слова: ферит, планування експерименту, органічні забруднювачі, каталізатор.

Постановка проблеми. Розвиток промислових технологій та сільськогосподарської діяльності призвів до вивільнення органічних сполук, що є потенційною загрозою для водних екосистем та здоров'я людини. Серед них такі забруднювачі, як пестициди, продукти хлорування та спалювання природного палива, фармацевтичні засоби та засоби особистої гігієни [1-6]. Щоб підвищити ефективність традиційних методів обробки забруднених стічних вод, використовують передові процеси окислення, які забезпечують потужне руйнування забруднювачів навколишнього середовища завдяки утворенню активних радикалів [7-10]. Серед них фотокаталітичні процеси $\epsilon$ перспективними завдяки високому ступеню деградації стійких забруднюючих речовин.

Аналіз останніх досліджень і публікацій. Проведений аналіз останніх публікацій і патентів із використання феритових фотокаталізаторів показав, що активно проводяться дослідження як в області синтезу нових речовин, так і в області їх використання [11].

Оптимізація фотокаталітичного процесу дуже важлива, оскільки трансформація вихідної забруднюючої сполуки та побічних продуктів iii окислення $є$ складною, а математичні моделі, необхідні для прогнозування і оптимізації, не завжди адекватно описують процес. Дослідниками було запропоновано кілька кінетичних моделей для точного опису розкладання органічних сполук у водній фазі шляхом окиснення під дією УФ-випромінювання в присутності перекису водню, використання фотокаталітичного процесу у видимій частині спектра. Розроблені кінетичні моделі описують здебільшого реакцію псевдопершого порядку. Пропонується також механізм, що передбачає утворення активних радикалів, що мають високу окислювальну здатність [12-15].

Постановка завдання. Важливим $\epsilon$ встановлення оптимальних умов проведення процесу. Визначення впливових незалежних факторів і використання можливостей методу планування експерименту дає змогу встановити параметри процесу, що дозволяють ефективно видаляти органічні сполуки.

Таким чином, метою цієї роботи було розроблення статистичної моделі для опису деградації 4-нітрофенолу (4-НФ). 
Виклад основного матеріалу дослідження. Для оцінки впливу вибраних факторів використовувався метод центрального композиційного планування експерименту. Визначали вплив таких параметрів, як концентрація фотокаталізатора $\left(\mathrm{x}_{1}\right)$ об'єм $\mathrm{H}_{2} \mathrm{O}_{2}\left(\mathrm{x}_{2}\right)$ та час обробки УФ-опроміненням $(\mathrm{t})$ на деградацію 4-нітрофенолу. Ядро центрального композиційного плану становив повний факторний експеримент (ПФЕ) типу $2^{n}$ за $n=3$.

План ПФЕ доповнювали деякою кількістю зоряних точок, координати яких залежать від прийнятого принципу оптимальності. Загальна кількість дослідів у разі такого планування визначається формулою

$$
N=2^{n}+2 n+n_{0},
$$

де доданки - відповідно число дослідів ПФЕ, зоряні точки та нульові точки.

Натуральні та кодовані значення рівнів для кожного з факторів наведені в таблиці 1.

Таблиця 1

Натуральні та кодовані значення рівнів факторів

\begin{tabular}{|c|c|c|c|c|c|c|}
\hline \multirow[b]{2}{*}{ Фактор } & \multicolumn{3}{|c|}{$\begin{array}{c}\text { Натуральні } \\
\text { значення }\end{array}$} & \multicolumn{3}{|c|}{ Кодовані } \\
\hline & 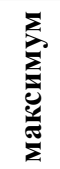 & 庰 & $\stackrel{\bar{E}}{\underline{\Xi}}$ & 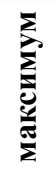 & 育 & \\
\hline Maca, г /100 мл & 1,5 & 0,5 & 1 & +1 & -1 & 0 \\
\hline Об'єм $\mathrm{H}_{2} \mathrm{O}_{2}$, мл / 100 мл & 1 & 0,5 & 0,75 & +1 & -1 & 0 \\
\hline Час, хвилин & 80 & 40 & 60 & +1 & -1 & 0 \\
\hline
\end{tabular}

Регресійна модель другого порядку була використана для опису експериментальних даних, згідно з рівнянням (2):

$$
\mathrm{Y}_{\mathrm{i}}=\beta_{0}+\sum \beta_{\mathrm{i}} \mathrm{x}_{\mathrm{i}}++\sum \beta_{\mathrm{ii}} \mathrm{x}_{\mathrm{i}}^{2}++\sum \beta_{\mathrm{ij}} \mathrm{x}_{\mathrm{i}} \mathrm{x}_{\mathrm{j}}+\varepsilon,
$$

де $\beta_{0}, \beta_{\mathrm{i}}, \beta_{\mathrm{ij}}$ - коефіцієнти при змінних, $\varepsilon$ - величина, що враховує вплив випадкових факторів.
Аналіз результатів розрахунку функції відгуку проводили, застосовуючи дисперсійний аналіз результатів.

Як функцію відгуку використовували ступінь розкладання 4-НФ.

$$
\% S=\frac{\left(C_{0}-C_{t}\right)}{C_{0}} 100 \%,
$$

де $C_{0}$ - початкова концентрація 4-НФ в розчині, $C_{t}$ - концентрація 4-НФ у момент часу $t$.

Ідентифікацію та визначення концентрації сполук проводили спектрофотометричним аналізом за допомогою спектрофотометра UV 5800 PC.

План експерименту складався 38 основних точок, 6 зіркових точок і 3 повторень у центральній точці, що налічує 17 експериментів, як показано в таблиці 2. Репліки в центральній точці дали змогу оцінити експериментальну помилку та адекватність моделі [16]. Експериментальні значення функції відгуку (ступень розкладання 4-НФ) для кожної комбінації факторів представлено в таблиці 2.

Таблиця 2

План проведення та результати експерименту

\begin{tabular}{|c|c|c|c|c|}
\hline № & $\mathbf{m}_{\text {кат }}$ & $\mathbf{t}_{\mathbf{0} \mathbf{0}}$ & $\mathbf{V}_{\mathbf{H 2 0 2}}$ & $\mathbf{S , ~ \%}$ \\
\hline 1 & 0 & 0 & 1,673 & 74,81 \\
\hline 2 & 1,673 & 0 & 0 & 70,6 \\
\hline 3 & 1 & 1 & 1 & 76,39 \\
\hline 4 & -1 & 1 & -1 & 51,37 \\
\hline 5 & 0 & 0 & 0 & 79,6 \\
\hline \hline 6 & 0 & 0 & 0 & 79,8 \\
\hline \hline 7 & 1 & -1 & 1 & 57,97 \\
\hline 8 & $-1,673$ & 0 & 0 & 77,5 \\
\hline 9 & 1 & 1 & -1 & 76,2 \\
\hline 10 & 0 & 0 & 0 & 79,8 \\
\hline 11 & 0 & 0 & $-1,673$ & 53,35 \\
\hline \hline 12 & 1 & -1 & -1 & 66,82 \\
\hline 13 & 0 & 1,673 & 0 & 90,95 \\
\hline 14 & -1 & -1 & 1 & 70,85 \\
\hline 15 & -1 & 1 & 1 & 89,26 \\
\hline 16 & 0 & $-1,673$ & 0 & 63,85 \\
\hline 17 & -1 & -1 & -1 & 45,22 \\
\hline
\end{tabular}

Результати дисперсійного аналізу для трьох факторів

\begin{tabular}{|c|c|c|c|c|c|c|}
\hline Фактор & Ефект & $\begin{array}{c}\text { Стандартне } \\
\text { відхилення }\end{array}$ & $\mathrm{t}(7)$ & $\mathrm{P}$ & $-95 \%$ & $+95 \%$ \\
\hline Головний & 80,07 & 2,623 & 30,524 & 0 & 73,86 & 86,27 \\
\hline $\mathrm{x}_{1}$ & 1,34 & 2,470 & 0,543 & 0,603 & $-4,49$ & 7,185 \\
\hline $\mathrm{x}_{1}{ }^{2}$ & $-6,11$ & 2,731 & $-2,238$ & 0,060 & $-12,57$ & 0,344 \\
\hline $\mathrm{x}_{2}$ & 14,36 & 2,470 & 5,815 & 0,000653 & 8,526 & 20,210 \\
\hline $\mathrm{x}_{2}{ }^{2}$ & $-3,72$ & 2,731 & $-1,362$ & 0,215 & $-10,17$ & 2,73 \\
\hline $\mathrm{x}_{3}$ & 13,34 & 2,470 & 5,402 & 0,001 & 7,506 & 19,190 \\
\hline $\mathrm{x}_{3}{ }^{2}$ & $-13,23$ & 2,731 & $-4,845$ & 0,0018 & $-19,69$ & $-6,776$ \\
\hline $\mathrm{x}_{1} \mathrm{x}_{2}$ & 0,81 & 3,221 & 0,251 & 0,8086 & $-6,807$ & 8,427 \\
\hline $\mathrm{x}_{1} \mathrm{x}_{3}$ & $-18,04$ & 3,221 & $-5,601$ & 0,000815 & $-25,66$ & $-10,427$ \\
\hline $\mathrm{x}_{2} \mathrm{x}_{3}$ & 5,325 & 3,22 & 1,6530 & 0,1423 & $-2,292$ & 12,942 \\
\hline
\end{tabular}


Статистична модель, отримана для квадратичного рівняння регресії, мала вигляд:

$$
\begin{array}{r}
\mathrm{S}(\%)=80,07+0,67 \mathrm{x}_{1}+7,18 \mathrm{x}_{2}+46,67 \mathrm{x}_{3}-3,05 \mathrm{x}_{1}{ }^{2}- \\
-1,86 \mathrm{x}_{2}{ }^{2}-6,62 \mathrm{x}_{3}{ }^{2}+0,405 \mathrm{x}_{1} \mathrm{x}_{2}-9,02 \mathrm{x}_{1} \mathrm{x}_{3}+2,66 \mathrm{x}_{2} \mathrm{x}_{3},(4)
\end{array}
$$

Високі значення коефіцієнтів у лінійних доданках $\left(\mathrm{x}_{2}, \mathrm{x}_{3}\right)$ порівняно 3 іншими коефіцієнтами означають, що вони $є$ найбільш впливовими в рівнянні (4).
Коефіцієнт при змінній $\mathrm{x}_{2}$ не тільки має найвище значення 3 всіх ефектів $(7,18)$, але $є$ також приблизно в 10,71 раза більшим, ніж $\mathrm{x}_{1}$. Коефіцієнти при парних взаємодіях факторів $\mathrm{x}_{1} \mathrm{x}_{2}(0,405)$ i $\mathrm{x}_{2} \mathrm{x}_{3}(2,66)$ мають, відповідно, значення, що в 17,8 і в 2,7 раза поступаються за відношенням коефіцієнту при $\mathrm{x}_{2}$.

На рис. 1 показано співвідношення між значеннями функції відгуку, визначеними за математичною моделлю та експериментально.

Залишки, отримані за квадратичною моделлю, випадковим чином розподіляються навколо експериментальних значень. Графік на рис. $1 €$ типовим для моделі, яка добре описує експериментальні дані.

Значущість факторів, що оцінювали за допомогою аналізу діаграми Парето, показана на рис. 2. Результати дисперсійного аналізу для всіх факторів наведено в таблиці 3 . На рис. 2 у вигляді гістограми представлені коефіцієнти при впливових факторах, через які проходить червона вертикальна лінія $(\mathrm{p}=0,05)$, що визначає значущість коефіцієнта i, відповідно, вплив у системі, який $\epsilon$ як позитивним так і негативним. Рівень значущості коефіцієнтів у порядку зменшення має вигляд: $\mathrm{x}_{2}>\mathrm{x}_{3}>\mathrm{x}_{1}$.

Позитивні значення коефіцієнтів при $\mathrm{x}_{2}, \mathrm{x}_{3}$ та $\mathrm{x}_{1}$ вказують на те, що зі збільшенням часу обробки, об'єму перекису водню та маси каталізатора значення функції відгуку також збільшуються. Протилежний вплив справляють доданки при $\mathrm{x}_{1}^{2}, \mathrm{x}_{2}^{2}$, $\mathrm{x}_{3}^{2}, \mathrm{x}_{1} \mathrm{x}_{3}$, що вказує на наявність екстремуму функції.

Значення, що вважаються оптимальними, були вибрані 3 урахуванням впливу кожного фактора на ступінь деградації 4-НФ, як показано на рис. 3-5. Високий ступінь розкладання 4-НФ (близько 90\%) відповідає кодованим значенням часу обробки, що наближаються

Рис. 2. Діаграма Парето 
до 1,0 та більше. Причому ступінь розкладання практично не залежить $\mathrm{m}_{\text {кат }}$ Крайові значення концентрації фотокаталізатора відповідають низьким значенням ступеня перетворення. Оптимальне значення відповідає точці з координатами $(0 ; 1)$ (рис. 3 )

Зелені напівкола в нижній площині графіка $S=f\left(\mathrm{t}, \mathrm{m}_{\text {ad }}\right)$ на рис. 3 показують області, де $S=46-66 \%$, що відповідають від'ємним значенням фактора $\mathrm{x}_{2}$.

Аналізуючи залежність ступеню перетворення від маси каталізатора та об'єму перекису водню, можна зазначити, що низькі значення ступеня розкладання 0-12\% відповідають низьким концентраціям як перекису водню, так і каталізатора. Ступінь деградації близько 91\% збігається 3 координатами точок на діагоналі квадрату. Тобто функція $\mathrm{S}$ чітко зростає лише тоді, коли один із двох факторів позитивний, а другий негативний.

Залежності, що показані на pис. 3-5 (зокрема області, що позначені помаранчево-червоними колами), вказують, що високий ступінь деградації 4-НФ відповідає експериментальним умовам:

- концентрації $\mathrm{H}_{2} \mathrm{O}_{2} 0,75$ мл / на 100 мл розчину та каталізатора 1 г / 100 мл розчину $\mathrm{NiFe}_{2} \mathrm{O}_{4}$;

- час обробки УФ-випромінюванням необхідно підтримувати на рівні, близькому до його максимального значення 60 хвилин.

Висновки. Представлені результати показують, що ферит нікелю $є$ ефективним каталізатором розкладу 4-НФ під дією УФ-випромінювання.

Використання методу планування експерименту 3 варіюванням факторів (концентрація $\mathrm{H}_{2} \mathrm{O}_{2}$, концентрація $\mathrm{NiFe}_{2} \mathrm{O}_{4}$, час обробки) дало змогу визначити, які саме змінні найбільш впливові в процесі деградації 4-НФ. Підвищення часу обробки призвело до збільшення ступеня деградації 4-НФ Вплив концентрації перекису водню та каталізатора має екстремальний характер. Встановлена така значимість факторів: $\mathrm{t}_{\text {об }}>\mathrm{V}_{\text {н202 }}>\mathrm{m}_{\text {кат }}$

Крім того, дисперсійний аналіз показав узгодженість між експериментальним даними та теоретично визначеними, тобто отримана математична модель адекватна.

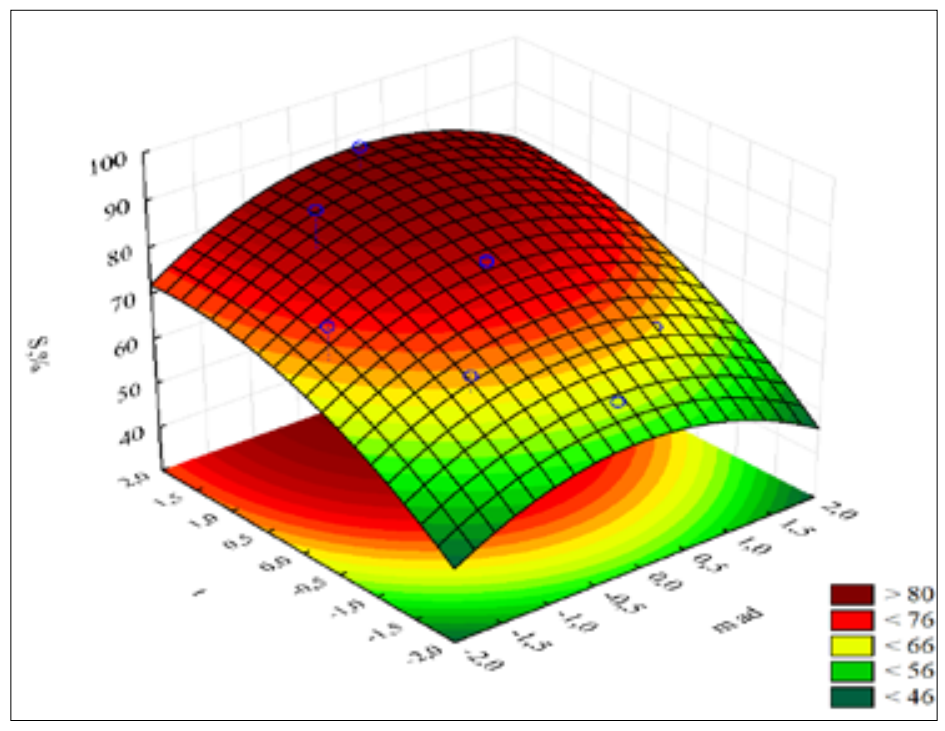

Рис. 3. Залежність ступеня деградації 4-НФ від часу обробки та маси каталізатора

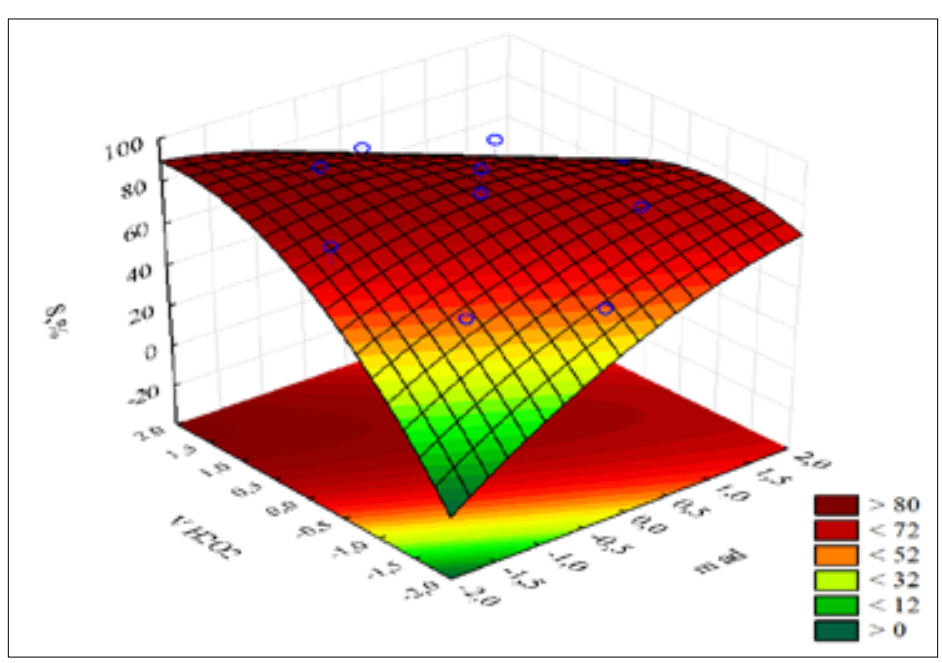

Рис. 4. Залежність ступеня деградації 4-НФ від об'сму перекису водню та маси каталізатора

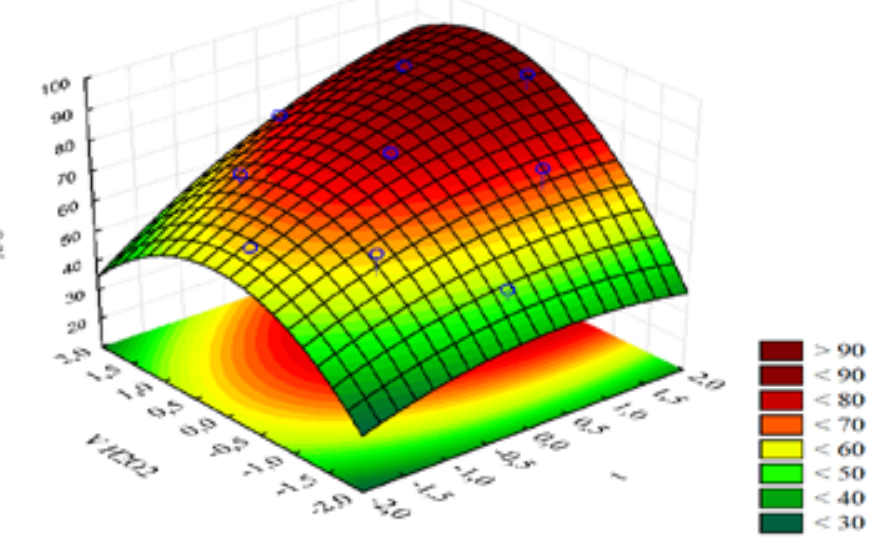

Рис. 5. Залежність ступеня деградації 4-НФ від об'сму перекису водню та часу обробки 


\section{Список літератури:}

1. Wen Y., Schoups G., Van De Giesen N. Organic pollution of rivers: Combined threats of urbanization, livestock farming and global climate change. Scientific reports. 2017. 7. P. 43289.

2. Lin C. et al. Contamination levels and potential sources of organic pollution in an Asian river. Water Science and Technology. 2017. 76. 9, P. 2434-2444.

3. Sun J. et al. Organic contamination and remediation in the agricultural soils of China: A critical review. Science of the Total Environment. 2018. 615. P. 724-740.

4. Shakir E., Zahraw Z., Al-Obaidy A.H.M.J. Environmental and health risks associated with reuse of wastewater for irrigation. Egyptian Journal of Petroleum. 2017. 26, 1, P. 95-102.

5. Assaad A., Pontvianne S., Pons M.N. Assessment of organic pollution of an industrial river by synchronous fluorescence and UV-vis spectroscopy: the Fensch River (NE France). Environmental monitoring and assessment. 2017. 189,5 , P. 229.

6. Saxena G., Bharagava R. N. Organic and Inorganic Pollutants in Industrial Wastes: Ecotoxicological Effects, Health Hazards, and Bioremediation Approaches. Environmental pollutants and their bioremediation approaches, CRC Press, 2017. P. 23-56.

7. Hu H. et al. Structural and mechanistic understanding of an active and durable graphene carbocatalyst for reduction of 4-nitrophenol at room temperature. Nano research. 2015. 8. 12. P. 3992-4006.

8. Sahu K., Singh J., Mohapatra S. Catalytic reduction of 4-nitrophenol and photocatalytic degradation of organic pollutants in water by copper oxide nanosheets. Optical Materials, 2019. 93. P. 58-69.

9. Dang T.T. et al. Nano-Catalysts in Ozone-Based Advanced Oxidation Processes for Wastewater Treatment. Current Pollution Reports. 2020. P. 1-13.

10. Egerton T.A. et al. The effect of UV absorption on the photocatalytic oxidation of 2-nitrophenol and 4-nitrophenol. Journal of Applied Electrochemistry. 2005. 35. 7-8, P. 799-813.

11. Wei S. et al. Molecularly imprinted tio2/wo3-coated magnetic nanocomposite for photocatalytic degradation of 4-nitrophenol under visible light. Australian Journal of Chemistry. 2016. 69. 6, P. 638-644.

12. Xiong Z. et al. Degradation of p-nitrophenol (PNP) in aqueous solution by a micro-size $\mathrm{Fe} 0 / \mathrm{O} 3$ process (mFe0/ O3): Optimization, kinetic, performance and mechanism. Chemical Engineering Journal. 2016. 302, P. 137-145.

13. Peng F. et al. Kinetics and mechanisms of enhanced degradation of ibuprofen by piezo-catalytic activation of persulfate. Chemical Engineering Journal. 2020. 392. P. 123818.

14. Zhou Z.G. et al. Degradation of organic pollutants by peroxymonosulfate activated by $\mathrm{MnO} 2$ with different crystalline structures: Catalytic performances and mechanisms, Chemical Engineering Journal. 2019. 374, P. 170-180.

15. Zhang $\mathrm{H}$. et al. Heterogeneous activation of hydrogen peroxide by cysteine intercalated layered double hydroxide for degradation of organic pollutants: Performance and mechanism. Journal of Colloid and Interface Science. 2019. 543, P. 183-191.

16. Кафаров В.В. Методы кибернетики в химии и химической технологии. Москва : Химия, 1985. 448 с.

\section{Frolova L.A. OPTIMIZATION OF CONDITIONS FOR THE PHOTOCATALYTIC OXIDATION OF 4-NITROPHENOL}

The development of industrial technologies and agricultural activities has led to the release of organic compounds, which is a potential threat to aquatic ecosystems and human health. These include pollutants such as pesticides, chlorination and combustion products of natural fuels, applied means and means of hygiene protection. To increase the efficiency of traditional methods of treatment of polluted wastewater using advanced oxidation processes that provide powerful destruction of environmental pollutants due to the formation of active radicals. Among them, the Fenton process is promising due to the high degree of degradation of persistent pollutants.

In addition, the scaling of chemical technologies - from laboratory research to industrial production is a difficult task and requires determining the optimal conditions for the process, a deep knowledge of the mechanism of reactions occurring in the system. This is necessary for the design and technological development of the main devices and determine the optimal conditions for their operation.

The process of decomposition of 4-nitrophenol in the presence of a ferrite catalyst is considered in the article. The experiments were performed using a reactor equipped with a UV emitter. The concentration of 4-nitrophenol was determined using a UV 5800 PC spectrophotometer. The statistical model was developed using the software package STATISTICA 10 and was based on the main reactions that occurred under the action of UV radiation in the presence of a ferrite catalyst. The calculated concentrations and degree of decomposition of 4-nitrophenol were confirmed by experimental results. A statistical model is obtained that is adequate. Using the method of central compositional planning of the experiment, the optimal process parameters were also determined, namely the concentration of the photocatalyst, hydrogen peroxide and processing time.

Key words: ferrite, experiment planning, organic pollutants, catalyst. 